DOI: https://doi.org/10.26512/les.v2i1.2953

\title{
O TEXTO E A CONSTRUÇÃO DA IDENTIDADE
}

\author{
Josênia Antunes Vieira \\ Veruska Ribeiro Machado
}

\begin{abstract}
This paper is about texts produced in an adult literacy course promoted by the Paranoá Community Centre (see Magalhães, in this number). The paper discusses literacy social practices and events in this community, as well as the political commitment of the group, the access to community life, to institutions and power. Thus, the texts show the construction of social and political identity in the group.
\end{abstract}

\section{Apresentação}

O presente artigo apoiou-se nos dados da pesquisa "O Texto na Alfabetização de Adultos", pesquisa desenvolvida na comunidade do Paranoá, cidade satélite de Brasília-DF. O grupo pesquisador investigou o letramento de adultos daquela comunidade, levado a efeito pelo Centro de Desenvolvimento e Culturado Paranoá. O Projeto estudou os textos produzidos pelo grupo de alfabetizandos, examinando as manifestações sociais de letramento refletidas nos textos produzidos por aquele grupo de alunos. De igual modo, delineou o perfil desse grupo por meio de parâmetros sociais relevantes: idade, sexo e estado civil. O estudo, ainda, identificou os motivos que levaram esses sujeitos à alfabetização. A ascensão social e profissional desse grupo, bem como os antecedentes escolares também foram comparados com a de seus familiares.

A produção textual dos alfabetizandos, no projeto citado, ensejou-nos novas reflexões sobre os eventos de letramento e sobre como eles contribuem para a construção da identidade desse grupo. Tal ponto de partida originou a pesquisa - O Papel do Letramento na Família e na Escola. Esse novo projeto visa ao reconhecimento do papel do contexto social da escrita e à identificação das redes estabelecidadas entre a escola e as famílias. Nesse artigo, desejamos observar como, por meio de práticas sociais letradas, no caso específico - os textos produzidos no projeto-, acontece o engajamento político, o acesso à vida comunitária, às instituições, ao poder. Por fim, analisaremos as manifestações de letramento desse grupo social, assim como a construção de sua identidade. 


\subsection{O contesto social do letramento}

Na voz de Barton e Ivanic (1991), é defendido que reconheçamos o papel do contexto social na escrita ainda que o contexto seja a vida cotidiana, o trabalho ou a própria comunidade educacional. A língua só é produzida ou interpretada em contextos sociais. Assim, o letramento é uma atividade social. Barton, (1994) afirma que a sua melhor descrição é em termos de práticas de letramento, com as quais as pessoas envolvem-se em eventos de letramento. Examinaremos a seguir as definições propostas por Barton para práticas e eventos de letramento.

No entendimento desse lingüista, eventos de letramento são definidos apropriadamente como a unidade básica do letramento. Em vários momentos de nossa vida diária, a escrita desempenha um determinado papel. Barton intitula tais momentos como eventos. Ao falarmos de eventos de letramento, é necessário descrever como de fato as pessoas utilizam o letramento. Um exemplo cotidiano de evento de letramento é aquele em que o pai lê uma história ao filho à noite; a leitura do jornal diário feita pelo pai ou, ainda, a lista de compras elaborada pela mãe. Em todos esses eventos de letramento, observamos padrões repetidos de interação. $\mathrm{O}$ termo eventos é mais amplo e inclui toda e qualquer atividade de letramento que envolva a palavra escrita.

Outro conceito relevante nesse artigo é o de práticas de letramento. O termo é usado em diversas disciplinas. Barton define tal conceito dizendo que há padrões culturais comuns ao uso da leitura e da escrita em uma situação particular. As práticas de letramento são práticas sociais atreladas à palavra escrita, mas que revelam práticas sociais mais gerais em uso em determinada comunidade. As práticas de letramento são as formas culturais gerais de utilização do letramento. Com elas direcionamos os eventos de letramento.

Se práticas e eventos de letramento são produtos sociais, torna-se imprescindível a contextualização da comunidade já pesquisada, principalmente pelo fato dessa apresentar trajetória histórica, com longo caminho percorrido na luta pela conquista e pela preservação de direitos adquiridos que, acima de tudo, contribuem para conscientizar a população sobre o poder social conferido aos eventos de letramento.

\subsection{A comunidade pesquisada}

A comunidade do Paranoá iniciou a sua história em 1961, ao ser concluída a construção da Barragem do Paranoá em Brasília. Os operários, trabalhadores da construção, por não terem moradia, invadiram as residências deixadas pelos engenheiros responsáveis pela obra. Essa invasão abriu as portas a outras invasões. Hou- 
ve a migração desordenada de vários grupos, principalmente, do Norte e do Nordeste brasileiro. A Vila Paranoá surgiu como local alternativo de moradia àqueles que buscavam melhores condições de vida. Após algum tempo, contudo, os invasores descobriram a ausência de infra-estrutura básica no Paranoá e também que, se realmente quisessem conquistá-las, deveriam lutar juntos para obtê-las.

O crescimento da invasão estimulou o movimento popular organizado. Tendo reivindicado junto ao governo o provimento de serviços básicos essenciais à população como a instalação de água, esgoto, luz, escola, posto de saúde, posto policial, perceberam as pessoas envolvidas no movimento popular que perdiam algumas lutas junto ao governo por utilizarem, como principal veículo difusor de idéias, mensagens escritas direcionadas às pessoas sem escolarização. Constataram que o insucesso das reivindicações populares residia no fato de a maioria das pessoas daquela comunidade não saber ler nem escrever.

Após essa descoberta, o movimento popular reivindicou do Estado a alfabetização de jovens e de adultos do Paranoá. Nenhuma das instituições de ensino oficial da época assumiu, de fato, a alfabetização do Paranoá. Por essa razão, a ação em defesa da alfabetização na comunidade não avançou. O movimento popular local solicitou, em 1986, o auxílio da Faculdade de Educação, da UnB que, em parceria com o movimento popular organizado local, implantou na comunidade o projeto de alfabetização com o objetivo de oferecer letramento aos jovens e aos adultos.

Não há professores da rede pública no projeto comunitário de alfabetização de adultos. As alfabetizadoras, em sua maioria pessoas simples da comunidade, atuam como voluntárias sendo consideradas heroínas anônimas, idealistas, que acreditam na formação da consciência política como ato libertador da pobreza e da miséria. Todas elas apresentam escasso preparo pedagógico, suprido pela dedicação à tarefa que realizam. Além da atuação de professores da Vila Paranoá, há a participação efetiva de professores e de alunos da Faculdade de Educação, da UnB. Outros profissionais ligados a diversas áreas do conhecimento da universidade colaboram com o projeto.

\subsection{Perfil da comunidade pesquisada}

Após a contextualização da comunidade do Paranoá, consideramos relevante traçar o perfil do grupo pertencente à alfabetização de adultos, visto os sujeitos ocuparem posições singulares no grupo e estabelecerem papéis e redes sociais que determinam a identidade do sujeito no contexto. Cada um dos participantes do projeto exerce diferentes papéis na comunidade e todo o uso individual privado ou público de letramento liga-o à redes de letramento de uso comunitário. Assim, por meio de características sociais significativas, a pesquisa identificou o sujeito da 
alfabetização de adultos da comunidade do Paranoá como sendo extremamente jovem, estando entre 15 e 25 anos; em sua maioria do sexo masculino; descendentes de migrantes nordestinos; detentores de pouca instrução e afeitos ao trabalho braçal. O sujeito da alfabetização de adultos procura o curso com objetivos e intenções definidos: ascender socialmente e resolver problemas práticos de letramento da vida diária. Busca ainda a alfabetização, pretendendo alcançar a realização pessoal, ao mesmo tempo em que alivia a cobrança social feita aos analfabetos pelos grupos letrados.

\section{$1.4 O$ contexto de letramento da comunidade pesquisada}

O contexto de letramento do Paranoá é restrito, para não dizer pobre. A ausência é quase total. Poucas bancas de revista, nenhuma biblioteca pública. No mundo do alfabetizando adulto, os materiais escritos são supérfluos. Se, por um lado, as experiências de letramento desse sujeito são pobres e incomuns, ficando os alunos pouco expostos a atos de escrita, com raro acesso a livros, a revistas e a jornais, não apresentando a menor intimidade com o letramento. Por outro, a linguagem do alfabetizando é altamente reveladora de sua identidade, mostrando-o ambivalente: ora ele toma consciência de sua limitação e inferioridade diante do mundo letrado, sentimento causado pela ausência de letramento, ora sente-se poderoso, capaz de lutar politicamente por seus direitos, reivindicando e sugerindo mudanças. Daí, porque a necessidade de incorporar novos eventos de letramento às práticas sociais letradas já usuais em sua vida.

\section{O texto e a construção da identidade}

O texto deriva de interação, de prática discursiva Na voz de Magalhães (1995), o texto é produto e um processo. É produto no sentido de ser resultado de um contexto de situação e de cultura particular. É um processo por exigir contínua escolha semântica. O sentido do texto estabelece-se, assim, pela relação do leitor com a intencionalidade do autor, nascendo dessa relação a coerência. Sendo o texto produto de prática discursiva, é instrumento de análise, agente esclarecedor do funcionamento da prática social, incluindo a prática dicursiva e o próprio texto. Além disso, o texto é um instrumento de análise contextualizado, tornando imprescindível para o seu completo entendimento, o estudo do contexto cultural e do contexto de situação.

Vygotsky (1962: 245), muito precocemente, já reconhecia a relevância do contexto ao afirmar que uma palavra adquire sentido no contexto em que aparece. Em contextos diferentes ela muda seu sentido, dizia ele. Halliday (1975) e Hymes (1972) também chamaram a atenção dos lingüistas para o fato de a língua variar 
de acordo com o contexto. Esses novos conceitos foram vitais para a lingüística moderna. A relevância do contexto no estudo da língua e do texto, em particular, é ratificada também por Mclane (1987:268) ao afirmar que os contextos são constituídos pelo o que as pessoas fazem e aonde e quando estão fazendo. Mcdermott (1976), de igual modo, afirma que as pessoas em interação formam entre si o contexto.

A quantidade expressiva de estudos a respeito do contexto, no entanto não minimiza a dificuldade em defini-lo. John-Steiner (1994:8) defende que, em alguns estudos, a concepção do contexto começa com trocas verbais e diálogos, mas vai além do aqui e agora para incluir a origem ou a fonte da troca e ao indagar sobre valores fornecidos cultural e historicamente (tais como as ferramentas e as práticas culturais formativas naquele contexto particular de interação social), descobre as práticas culturais padronizadas. É inegável o papel do contexto na construção discursiva do texto, todavia é a linguagem usada em determinada ocasião social que determina o formato dos textos produzidos, constituindo o que chamamos gênero discursivo, que, por sua vez, formata o texto em termos de sequiência, de textura, de etapas e de modos de organização.

Muitos investigadores estudaram o desenvolvimento e os usos iniciais do letramento em casa, em família, como John-Steiner \& Roth (1983), Barton (1994). Do mesmo modo, as variações culturais em comunidade e em família têm sido objeto de estudo de lingüistas, de antropólogos e de etnógrafos que identificaram diferentes metáforas para o letramento. Barton (1994) afirma haver metáforas relacionadas à doença. O iletrado é tido como doente. Em outras metáforas, a ausência de letramento é associada à incapacidade. No Canadá, o iletramento está associado à criminalidade e nos Estados Unidos a aspectos econômicos. No Brasil, a sociedade sente pena dos iletrados e os associa à pobreza e à falta de liberdade. Na opinião de Barton, a melhor metáfora para o letramento é a ecológica. Afirma ele existirem nichos ecológicos que mantêm e alimentam formas diferentes de letramento que interagem entre si. Assim, o indivíduo é parte, mas ao mesmo tempo interage com o letramento, modificando-o.

\subsection{Práticas sociais de letramento}

A diversidade de usos da escrita contribui para a constituição de várias práticas sociais (comerciais, políticas, etc) e para a construção das relações sociais e das identidades dos sujeitos. Tais usos são derivados das práticas discursivas de letramento, que incorporam eventos de letramento - atividades particulares de escrita, com papel social - e formas culturais de utilização do letramento, com preconcepções ideológicas, que, por sua vez, conduzem as pessoas a outros eventos de letramento. O indiví- 
duo, antes do letramento, havia participado de reduzido número de eventos de letramento, mas à medida que o seu conhecimento do mundo letrado aumenta, também aumentam as necessidades de paticipação em novos eventos. A exemplo do fato, podemos ilustrar com a prática social de escrever cartas. Até então, escrever para outras pessoas era uma prática social dos outros . Agora, passa a ser evento de letramento concreto na vida do novo usuário da língua escrita..

As práticas discursivas de letramento são matrizes históricas que determinam a produção e a interpretação de textos orais ou escritos, com emissores e receptores concretos (Magalhães, 1995). As práticas discursivas de letramento revelam o caráter institucional ou comunitário, constituindo identidades, valores e crenças mediadas pelo meio escrito. Vygotsky (1978: 118) afirma, a esse respeito, que o letramento é adquirido lentamente, sendo ligado às funções da linguagem na língua das crianças e aos usos particulares do discurso escrito.

O discurso, compreendido como prática social, constitui as identidades sociais. Segundo Fairclough (1992), o discurso é uma prática não apenas de representação do mundo, mas também de sua significação, construindo o significado do mundo. O discurso contribui para configurar todas as dimensões da estrutura social que, direta ou indiretamente, moldam e restringem as normas e as convenções, assim como as relações, as identidades e as instituições que estão por trás delas.

A língua escrita contribui para organizar contextos ou domínios institucionais e comunitários. O conceito de prática discursiva de letramento é indispensável à compreensão de que a escrita apresenta usos particulares que dependem da experiência textual e dos propósitos dos membros da comunidade (Magalhães, 1995). O texto obedece a regras que não provêm somente da coerência textual interna, mas das condições extra-textuais de enunciação. De qualquer maneira, é extremamente difícil perceber o sentido de um texto sem um mínimo de conhecimento histórico sobre as condições de seu aparecimento.

Na opinião de Barton (1994), as pessoas atribuem sentido ao letramento como resposta a um fenômeno social. A construção social do letramento repousa na raiz de suas atitudes em direção ao letramento e às ações. O letramento está enraizado em contextos institucionais que, por sua vez vez, moldam as práticas e os significados sociais, atrelando-os à leitura e à escrita. Desse modo, a leitura e a escrita tomam significado social: podendo ser um ato que desafia ou provoca solidariedade, um ato de conformidade ou um símbolo de mudança. As pessoas afirmam suas identidades por meio do letramento. As atividades que envolvem o letramento são muitas e variadas, não sendo realizadas apenas na escola, na família ou no trabalho. Elas acontecem no dia-a-dia das pessoas e da comunidade.

É justamente esse contexto comunitário que julgamos favorável ao estudo dos eventos de letramento ocorridos nas salas de aula de alfabetização do Paranoá. 
Como fruto de levantamento geral das práticas de letramento no contexto de alfabetização, podemos dizer que os documentos de origem reivindicatória e as produções escritas que contenham experiências pessoais ou comunitárias, passadas ou cotidianas predominam nessa comunidade educacional. Os eventos, atividades particulares em que o letramento desempenha papel social, podem envolver desde escrita de cartas até lembretes ou descrições de fatos ocorridos.

\subsection{Os eventos de letramento}

As práticas sociais de letramento na comunidade são altamente valorizadas no curso de alfabetização de adultos do Paranoá, ocorrendo aproximação de tais práticas ao trabalho do aufabetizador em sala de aula. Considerando toda a história do Paranoá, destacamos a depuração da consciência política da população dessa cidade satélite. Por isso, nos eventos de letramento mais comuns na comunidade são produzidos os textos orais e escritos ligados às reivindicações populares, às manifestações políticas, à denúncia da dura realidade enfrentada pelos seus moradores. E nesse contexto que são conduzidos os eventos de letramento escolar, refletindo, em torno da escrita de textos, as experiências pessoais, que retratam a realidade de cada alfabetizando pertencente a essa comunidade. Os alfabetizandos, nesses momentos, aproveitam a oportunidade para escrever a um determinado público, na maioria das vezes, autoridades políticas.

\subsection{Textos escritos}

Apresentamos a seguir alguns textos produzidos pelos alunos do Curso de Alfabetização de Adultos e, a partir deles, examinaremos a construção da identidade desse grupo.

um levantamento sobre a nossa saúde Aqui no paranoá náo é boa não tem meticas suficiente para a tender a população mas de setenta por cento vai ao posto $e$ volta cem cer atendido falta da meticas, também falta alimentação progidica a saúde das crianças eate mesmo de nos a adultos a limentação é muito importanti Para todos nos poriso que nos obnemos ter uma boa alimentação para fazer bem a nossa saúde. 
Nesse exemplo, identificamos com nitidez a consciência crítica do alfabetizando ao explorar o tema em forma de denúncia "não tem meticas suficiente para atender a população" e também pelo desenvolvimento e continuação do tema, envolvendo outros problemas. O texto retrata a realidade do sistema hospitalar brasileiro que atravessa crises extremamente sérias. Vemos, além desses aspectos, a associação direta de boa saúde com boa alimentação, crença que faz parte da nossa sociedade como uma espécie de mito.

A maioria das produções escritas dos alfbetizandos são cartas de origem reivindicatória. Ressaltamos que esse tipo de texto auxilia o alfabetizando em sua sobrevivência, uma vez que grande parte das cartas reclama por segurança e melhoria das condições hospitalares, como mostramos anteriormente. Por meio dessas cartas, avaliamos o papel fundamental do letramento para a conquista de melhoria de vida. Assim, o sujeito do Paranoá, aos poucos, conscientiza-se que, somente incorporando as práticas de letramento, terá condições de lutar por seus direitos, pois vivemos em sociedade letrada que exclui, em muitos níveis, os iletrados.

Senho cecretario da Educação

Peço urgente Segurança na escola e limpeza na

sala de aula precisamos de luz na sala

para que possamos estuda espero

se atendido

As criança do Paranoá

São muito triste por que não

tem saúde não temos

condesois de viver com

diginidade porque falta

hospital saniamento

básico

segurança

Nessas cartas reivindicatórias, o alfabetizando reclama por segurança, saúde e limpeza nas escolas como temas mais freqüentes. Tais textos originam-se na vida diária; nas dificuldades enfrentadas cotidianamente. Pouco a pouco, o alfabetizando descobre que suas reclamações só serão atendidas se forem feitas por escrito, conforme exigência das instituições. É notório que, em muitos dos textos analisados, há uma exaltação dos êxitos atingidos por meio da ação comunitária, confirmando ao alfabetizando o poder do letramento na defesa de interesses do grupo. 
Senhor Secretario

O Problema do colégio é que falta segurança, Senho no nossoco colégio também falta limeza.

Sobri a iluminação do colégio a nossa sala nào tinha lus mas agora tem Porque nas comprou se nas não tivecê comPrado

Ainda estava no escuro, e nos comProu as lamPadas

Para a noça cala

Verificamos, nesse exemplo, o levantamento de um problema cotidiano "O problema do colégio é que falta segurança"e logo depois a ênfase no modo de resolver o problema, mostrando a ação da comunidade "e nos comProu as lamPadas". Ademais, o texto denota a constante participação dessa comunidade em todas as conquistas sociais, muitas vezes, recheada de longos sacrifícios e de árduas lutas.

As pessoas traçam objetivos e o letramento deve servir a essas metas. As pessoas lêem e escrevem para concretizar desejos e alcançar propósitos. As pessoas querem que suas vozes sejam ouvidas. A leitura e a escrita compartilham desse processo de manifestação social. No Paranoá, os eventos de letramento produzidos em sala de aula são praticamente todos ligados às causas sociais, determinando novo valor à voz do alfabetizando. Citamos, aqui, as idéias defendidas por Foucault (1969) e Fairclough (1992) a respeito da concepção do sujeito com relação à resistência, à mudança e ao poder do discurso. Os eventos discursivos de letramento no contexto de alfabetização do Paranoá caracterizam o sujeito como agente de mudança, anulando a postura reproducionista da fala de acordo com o momento e com a adequação. Essa característica é observada principalmente em textos que tratam de política. Demonstraremos essa concepção desse sujeito, inconformado e defensor de seus direitos de cidadão, em dois textos com o tema das eleições.

\section{Lembrete:}

Fernando Henrique

esse lembrete significa e soubre

a canditanera do sr presidente

presidente eleito com uma desele

e seu prestigio como presidente

será desmoralizado por todas

as cidadões que colocaram,

na presidência. 
lembrete ao novo presidente Fernando enrique vai para o puder mais o basta em deselece dele o povo esla cara ele na rua se as familharis mandarem bilhetinhos pedendo eslaliararas o filme dele será quemado esta queremos dezer que se eli roubar dinheiro dos povos que deram o seu voto e confiaram nele mas ele presiza do motivo para as pessoas confia nele se não ele era expulso do congresso como um cão zinho com arabo emtre das perna.

Vemos também, nesses exemplos, como os eventos de letramento de sala de aula estão fortemente ligados aos contextos sociais que modelam as práticas e os significados sociais vinculados à leitura e à escrita. É relevante observarmos, no primeiro exemplo, a presença do "outro", constituindo uma heterogeneidade quando o alfabetizando afirma: "será desmoralizado por todas os cidadões que colocaram, na presidência". Esse traço confirma a dialogização interna do discurso, defendida por Bakhtin (1979), como a representação no discurso do discurso do outro. Toda a fala é determinada de fora da vontade do sujeito, exterior ao sujeito no discurso. Na dialogização interna do discurso, as palavras são sempre e inevitavelmente as palavras do outro. Nenhuma palavra é neutra, mas inevitavelmente carregada, habitada e atravessada pelos discursos vividos em sua existência socialmente sustentada.

Além desse fato, o exemplo 2 mostra-se riquíssimo de marcas relativas à delimitação do contexto imediato e cultural. O locutor faz uma advertência ao novo presidente em relação ao roubo, referindo-se aos fatos ocorridos no Brasil durante o governo Collor. Esse texto mostra a prática social: "familharis mandarem bilhetinhos, roubar dinheiro dos povos que deram o seu voto, expulso do congresso". Todos esses sintagmas referem-se aos costumes e hábitos dos governantes brasileiros; ressalva feita em relação ao último sintagma que remete ao episódio de impedimento ao ex-presidente Collor.

Segundo Barton (1994), os letramentos são identificados culturalmente. Os diferentes letramentos estão associados aos diferentes domínios da vida, tais como a casa, a escola, a igreja e o trabalho. Há lugares na vida em que as pessoas atuam e usam a língua diferentemente. As regras sociais subjacentes à ação das pessoas em diferentes domínios são diferentes. Qualquer domínio pode ser significante. É nesse ponto que o engajamento social e político de alguns membros do curso de alfabeti- 
zação contribui para o letramento. Esses buscam a linguagem para compreender melhor a realidade social e ao mesmo tempo capacitam-se para elaborar argumentações vivas e representativas de seu meio social. Tudo isso porque eles, agora, incorporaram novas práticas de letramento a sua vida.

\section{O salário minimo \\ o salário minimo não é suficiente para uma família brasileira sobreviver \\ E uma vergunha, com a caristia que esta \\ as coisas \\ $O$ assalariado sofautafaze milagre,} Ainda mais com essa URV, serra que vai d certo?

O exemplo demonstra conhecimento da realidade social por parte do alfabetizando, que, descontente com as dificuldades sociais enfrentadas, afirma ser necessário realizar mudanças. Devido ao interesse pela economia e pela situação do povo, notamos que o aluno, provavelmente, acompanha notícias sobre a situação do país, seja por meio de participações em reuniões comunitárias para debates, seja buscando de outras maneiras a interação social.

Discurso é um modo de ação sobre o mundo e os outros, sendo também um modo de representação da realidade. As identidades sociais são constituídas pelo discurso, compreendido como prática social. As posições dos sujeitos são, então, heterogêneas; variáveis de acordo com o contexto social. Considerando esses pontos, traçamos algumas implicações entre o texto e a construção da identidade dos alfabetizandos.

A identidade é variável de acordo com o contexto social e esse contexto está na própria linguagem. Partindo deste princípio, consideramos que a incorporação de novos eventos de letramento em sala de aula constrói facetas diferentes nas identidades dos alfabetizandos. Primeiramente, ressaltemos o fato de que os alfabetizandos precisam de resolver problemas de letramento em seu cotidiano. Um dos fatores agregado a essa questão é o problema da burocracia aliado à política. Ora, a partir do momento em que os sujeitos, em práticas de letramento em sala de aula, despertam para a consciência política, eles encaram essa tomada de consciência política como ato libertador da pobreza e da miséria dentro da comunidade. Nesse momento, ao participarem de eventos de letramento que possuem carga político-reivindicatória, ocorre formação da consciência política, implicando mudanças na linguagem, e, conseqüentemente, influenciando a identidade dos alfabetizandos.

A história percorrida pela comunidade na luta pela preservação e pela conquista de direitos contribuiu para a construção de nova identidade, que, pelo 
letramento, oferece novo poder ao alfabetizando adulto. Segundo Fairclough (1989), esse novo poder é dado aos sujeitos ao incorporarem as práticas sociais de letramento aos eventos da vida diária. As atuais posições sociais dos sujeitos refletem identidade diferenciada daquela anterior ao letramento. A significativa contribuição que os textos produzidos no Paranoá trazem à construção da identidade dos alfabetizandos é o incentivo à participação em novos eventos de letramento que os identificam na sociedade, encorajando-os a enfrentar as diversas situações do dia-a-dia. Além disso, a recente identidade qualifica os alfabetizandos como membros letrados da comunidade do Paranoá.

\section{Referencias Bibliográficas}

Bakhtin, M. Marxismo e filosofia da linguagem. São Paulo: Hucitec, 1979.

Barton, D \& Ivanic, R. Writing in the community. Written communication annual, London: Sage, 1991.

Barton, D. Literacy: an introduction to the ecology of written language.Oxford, UK: Blackwell, 1994.

Da Silva, J. V. et ai. O texto na alfabetização de adultos. Brasília, UnB. pesquisa inédita, 1995.

Fairclough, N. Discourse and social change. Cambridge: Polity Press, 1992.

Foucault, M. Arqueologia do saber. Trad. L. F. B. Neves. Rio de Janeiro: ForenseUniversitária, 1987 (1969).

Halliday, M. Learning how to mean. London: Edward Arnold, 1975.

Hymes, D. Models of the interaction of language and social life. In: Gumperz, J. J.\& Hymes, D. (eds.) Directions in sociolinguistics. New York: Holt, Rinehart \& Winston, 1972, pp. 35/71.

Hamilton, M.; Barton, D. \& Ivanic, R. Worlds of literacy. Ontario Institute for Studies in Education. Toronto, 1993.

Mclane, J. B. Interaction, context and the zone of proximal development In:

Hickman, M. Social andfimctional approaches to language andthought Orlando, FL: Academic Press, 1987, pp. 267-286.

Mcdermott, R. Kids make sense: an ethnographic account of the interactional management of success and failure in one first-grade classroom. Stanford, Stanford University, CA, unpublished doctoral dissertation, 1976.

Magalhães, I. Práticas discursivas de letramento: a construção da identidade em relatos de mulheres. In: Kleiman, A. (org.) Os significados do letramento. Campinas: Mercado de Letras, 1995, pp. 201-235.

Magalhães, M. I. S. \& Batista, E. E. Interação, texto e contexto na alfabetização de 